\title{
Impacto económico de la discrecionalidad de la política arancelaria en El Salvador: Impacto fiscal, 1998-2000 (II)
}

Roberto Góchez Sevil.LA*

\section{A. El primer caso: Las reducciones y exenciones arancelarias.}

El proceso de estimación fiscal de las salvaguardias que contemplan reducciones y exenciones arancelarias es relativamente sencillo, pues estas medidas suponen una pérdida de recursos de la Hacienda Pública producto de rebajas arancelarias hechas por medidas discrecionales y con poca base legal. Es posible estimar esals pérdidas fiscales determinando el saldo entre lo que hubiera correspondido pagar por la importación de un producto con los aranceles legales anteriores - los mayores- y lo pagado efectivamente con los nuevos aranceles impuestos - los menores- por salvaguardia. En este tipo de medidas, dado que las decisiones discrecionales han reducido los aranceles, se tiene un saldo con signo negativo entre ambas cifras, lo que significará pérdidas de recursos por parte de Estado, que tienen por contraparticla "ganancials fiscal-

\footnotetext{
* Fil alutor es Investigador Fconómico del Áreal de Macroeconomia y Desiarollo de la Fundación Nacional para el Desaltrollo (Fl N1)b). Fil presente trabajo ha sido posible gracials al apoyo cle (OXFAM (i.13. y OXFAM América.
}

Impacto económico de la discrecionalidad de la político arancelario en El Salvador 
les" extraordinarias para algunas empresas por concepto de una menor tributación por los menores aranceles a sus importaciones.

Para cuantificar este tipo de medidas, se ha procedido a determinar el monto de la exención, tomando únicamente las importaciones provenientes de fuera de la región centroamericana, puesto que la región posee libre comercio en términos generales, en virtud del Tratado General de Integración Económica. Es sobre las importaciones centroamericanas que se estima lo que hubiera correspondido pagar en virtud de los aranceles anteriores, y lo que se pagó efectivamente, debido a los nuevos y menores aranceles salidos de las salvaguardias, el saldo entre ambas es imputado entonces como una pérdida fiscal en las estimaciones.

Un argumento que es igualmente aplicable para los otros casos particulares, es que, en algunas subpartidas arancelarias la determinación del arancel anterior a la salvaguardia ha presentado la dificultad que sus aranceles habían sido previamente modificados por medidas similares anteriores; en estos casos se ha optado determinar el arancel original previo a cualquier salvaguardia, es decir aquel que tenía con anterioridad a cualquier modificación derivada de la aplicación del artículo 26 del CRAAC u otra modificación ministerial de los aranceles; esto se hace asi pues al ser un procedimiento inválido la modificación ministerial de los aranceles, el arancel que correspondería "legalmente" sería aquel que tenía originalmente la particla. Fn muchos casos el arancel anterior se puede evidenciar en el resto de países centroamericanos, pues gran parte de las salvaguardias de hecho han roto la equiparación alcanzada en el Arancel de Importación entre los países de la región. Cuando no fue posible hacer esa estimación. se tomó el arancel surgido de la salvaguardia anterior.

\section{i. El maíz amarillo y blanco}

Estal medida fue emitida por el Ministro de Economía, Ecluardo Zablah-Touché, el de Hacienda, Manuel Enricpue Hinds, y el de Agricultura y Ganaderia, Ricardo Quinónez, por medio de la resolución tri-ministerial 30.3 bis, publicacla en el Diario O/icial 83 , Tomo 335, el 9 de Mayo de 1997. En uno de los considerándos, estos funcionarios aducen que el COMRIEDRE (antecesor del COMIECO) autorizó a los paises para aplicar mecanismos naciona-

\section{0}


les que para fijar aranceles. y de ahí parecen deducir que son cllos los que tienen competencia en la materia. La resolución modifica los aranceles para diferentes varieclades de maiz amarillo, para el máz. blanco, y para una variedad de sorgo, sin siquiera establecer que se hace uso del artículo 26 del CRAAC.

Cuadro No. 1

Salvaguardia del Maíz

\begin{tabular}{|c|c|}
\hline Descripción & $\begin{array}{l}\text { Reclucciones arancelariats y aperturas paral } \\
\text { diferentes particlas del maiz }\end{array}$ \\
\hline $\begin{array}{l}\text { Resoluciones Ministeriales } \\
\text { que la emitierono } \\
\text { modificaron }\end{array}$ & 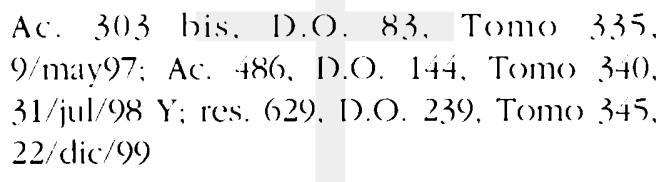 \\
\hline $\begin{array}{l}\text { Arancel aplicado por } \\
\text { salvalguardial al cadla } \\
\text { particla arancelaria }\end{array}$ & 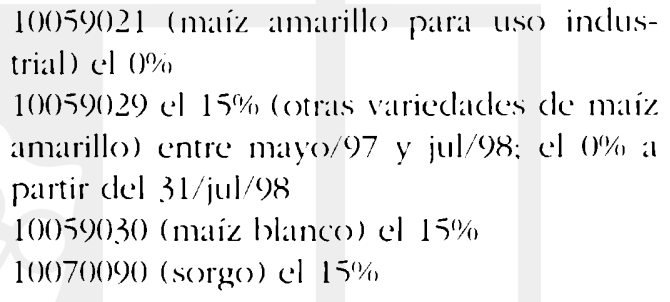 \\
\hline $\begin{array}{l}\text { Arancel que conrespondería } \\
\text { sin salvaguardia a cacla } \\
\text { partida }\end{array}$ & $\begin{array}{l}10059021 \text { el } 20 \% \text { (Arancel anterior y de } \\
\text { res. CAAC } 51-94 \text { ) } \\
10059029 \text { el } 20 \% \\
10(059030 \text { el } 20 \% \\
10070090 \text { el } 20 \% \text { (Arancel anterior y de } \\
\text { res. CAAC } 51-94 \text { ) }\end{array}$ \\
\hline $\begin{array}{l}\text { Fmpresas importadoras } \\
\text { por particla según datos } \\
\text { de Directorio de } \\
\text { importadores del BCR. }\end{array}$ & $\begin{array}{l}\text { De la 10050(021: Fmpresals Inclustriales San } \\
\text { Benito, Diana, Incoca, Moore Comercial, } \\
\text { Bocadelli } \\
\text { De la 10059029: Empresas Industriales San } \\
\text { Benito, Alpe, Incoca, Moore, Bocadelli, Pro- } \\
\text { ductos Alimenticios Sellos De Oro } \\
\text { De la 10059030: Guerra Umaga, Vigil } \\
\text { Gómez, Díaz, Jopaflo International, Haris, } \\
\text { Comercial Amac, Empresas Inclustriales San } \\
\text { Benito, Granos De Centro América. }\end{array}$ \\
\hline
\end{tabular}




\begin{tabular}{|c|c|}
\hline & $\begin{array}{l}\text { De la } 10070090, \text { Empresas Industriales San } \\
\text { Benito }\end{array}$ \\
\hline $\begin{array}{l}\text { Importaciones de fuera } \\
\text { de Centroamérica } \\
1998-2000\end{array}$ & $\begin{array}{l}10059021 \text { US\$ } 26,791,752 \\
10059029 \text { US\$ } 75,115,995 \\
10059030 \text { US\$ } 9,351,379(1998-1999) \\
10070090 \text { Ninguna }\end{array}$ \\
\hline $\begin{array}{l}\text { Pérdiclas fiscales por } \\
\text { particla arancelaria }\end{array}$ & $\begin{array}{l}1998-20001 \text { US\$ } 5,358,350 \\
10059029 \text { US\$ } 15,023,199 \\
10059030 \text { US\$ } 467,569(1998-1999)\end{array}$ \\
\hline $\begin{array}{l}\text { Perdidas fiscales totales } \\
\qquad(1998-2000)\end{array}$ & US\$ $20,849,118$ \\
\hline
\end{tabular}

Nota: En el cálculo no se han estimado valores para 1997, cuando fueron emitidas las medidas, con lo cual aumentarian las estimaciones; el arancel de la partida 10059029 fue reducido a $0 \%$ a mitad de 1998; sin embargo, no es posible hacer estimaciones interanuales, por lo que se debió estimar usando el $(0 \%$ para todo el año, lo que puede reducir las estimaciones en algún porcentaje, aunque es atenuado porque en 1998 es el año en que las importaciones por esta particla fueron menores; la particla 10070090 sólo presenta importaciones de Centroamérica para todo el periodo; para el 2000 no ha sido contabilizado las estimaciones de la particla 10059030, maíz blanco, ya que hubo una modificación de la misma.

Posteriormente la salvaguardia fue modificada nuevamente, por un nuevo acuerdo tri-ministerial de los mismos funcionarios (Ac. 486, D.O. 144, Tomo 340, 31/jul/98), en dónde se dio una exención de aranceles para la partida 10059029; la resolución COMIECO 29-98 del 18/dic/98, hizo permanente el arancel para el maíz blanco establecido por salvaguardia, y el resto de medidas fueron hechas "permanentes" hasta la resolución 73-2001, que fue tomada el 16 de marzo del 2001. Esta salvaguardia como puede verse había sido prorrogada desde 1997 por numerosas resoluciones del COMIECO, y misteriosamente luego del escándalo de los componentes de baterías fueron convertidas en modificaciones permanentes del arancel.

Las importaciones de las tres partidas son, en su mayoría de productos de Estados Unidos. En total, las importaciones (tres subpartidas) provenientes de este país, ascienden a ochenta y nueve millones de dólares (US\$ 89 Millones) entre 1998 y el 2000.

\section{2}


Como puede ser visto, esta medida, representa una considerable cantidad de recursos que el Estado ha perdiclo en razón del uso indebido de las salvaguardias, particularmente de la aplicarción de una medida por funcionarios del Poder Fjecutivo de la anterior administración. Esta medida por si sola representa casi el $50 \%$ de las pérdidas que han sido estimadas entre 1998 y el 2000, cifra que dice por si misma el impacto fiscal de la misma.

\section{ii. La harina de residuos de soya}

Esta medida fue emitida por el Ministro de Economía, Fduardo Zablah-Touché, el de Hacienda, Manuel Enrique Hinds, por la resolución 158, publicada en el Diario Oficial. No. 96 (Il Parte), del 28 de Mayo de 1997. En los consideránclos de esta medida se establece que con previas mediclas bi-ministeriales se habian reduciclo los aranceles para algunos productos hasta un 1\% o 3\%, y que es "necesario uniformar los niveles" para llevarlos al $0 \%$.

En esta medida ni tan siquiera enuncia el artículo 26 del CRAAC para aducir la supuesta atribución de modificar aranceles o emitir salvaguardias, y tal pareciera que de suyo los Ministros asumen esá atribución, en casos que claramente no constituyen ni siquiera una causal de salvaguardia por desabastecimiento. La partida otorgó exención arancelaria para la Harina de residuos de soya de la partida 23040010, que tenía un arancel del 5\%, que era el arancel meta que había sido negociado por los países de la región.

Esta media ha implicado la pérdicla fiscal de 4 millones de cólares clurante los tres años que han sido estimados; fue convertido en cambio permanente por la resolución COMIECO 73-2001, a partir del $1^{\circ}$ de abril del 2001, situación que obviamente encubre el origen de la medida. 
Cuadro No. 2

Salvaguardia de harina de soya

\begin{tabular}{|c|c|}
\hline 1)escripción & $\begin{array}{l}\text { Exención arancelaria para la particla de Ha- } \\
\text { rina de despojos de Soya de la partida } \\
23040010\end{array}$ \\
\hline $\begin{array}{l}\text { Resoluciones Ministeriales } \\
\text { que la emitieron o } \\
\text { modificaron }\end{array}$ & $\begin{array}{l}\text { Res. } 157 \text {, D.O. } 96 \text { Parte II, Tomo } 335,28 / \\
\text { may/97 y Res. 90, D.O. 65; Tomo 343, 12/ } \\
\text { abr/99; res. 629, D.O. 239, Tomo 345, 22/ } \\
\text { dic/99 }\end{array}$ \\
\hline $\begin{array}{l}\text { Arancel aplicado } \\
\text { por salvaguardia }\end{array}$ & $0 \%$ \\
\hline $\begin{array}{l}\text { Arancel que } \\
\text { correspondería sin } \\
\text { salvaguardia }\end{array}$ & $5 \%$ \\
\hline $\begin{array}{l}\text { Empresas importadoras } \\
\text { por partida según datos } \\
\text { de Directorio de impor- } \\
\text { tadores del BCR. }\end{array}$ & $\begin{array}{l}\text { Empresas Industriales San Benito, Benítez } \\
\text { Salmeron, Alpe, INCOCA, Moore Comer- } \\
\text { cial, Productos Alimenticios Sello de Oro, } \\
\text { Comercial AMAC, Productos Cárnicos. }\end{array}$ \\
\hline $\begin{array}{l}\text { Importaciones de fuera } \\
\text { de C.A. }\end{array}$ & US\$ $81,613,884$ \\
\hline $\begin{array}{l}\text { Pérdidas fiscales totales } \\
1998-2000\end{array}$ & US\$ 4,080,694 \\
\hline
\end{tabular}

Nola: Fl monto total que ha sido estimado podría ser mayor si le sumáramos las pérdidas fiscales de los aǹos precedentes, derivado de anteriores medidas de salvaguardia. El arancel previo es el que le correspondía previo a cualquier salvaguardia y era el arancel meta centroamericano.

Esta media ha implicado la pérdida fiscal de cuatro millones de dólares durante los tres años que han sido estimados; fue convertido en cambio permanente con la resolución COMIECO 73-2001, a partir del $1^{\circ}$ de abril de 2001, situación que obviamente encubre el origen de la medida.

\section{i. Explosivo (Nitrato de amonio).}

Los Ministros de Economía y Hacienda, de la administración Calderón Sol emitieron y pusieron en vigencia esta medida por medio 
de la resolución 277, en el Diario Oficial 240, del 23 de diciembre de 1998. En esta medicla se aduce desabastecimiento de materias primas en la región, lo que perjudica a las empresas que la usan, por lo que se decreta la exención arancelaria $(0 \%)$ del nitrato de amonio incluido en la partida 36020010 (explosivo preparado).

\section{Cuadro No. 3}

\section{Salvaguardia de explosivos}

\begin{tabular}{|c|c|}
\hline Descripción & $\begin{array}{l}\text { Exencion de aranceles para la particla } \\
36020010 \text { (explosivo preparado a base de } \\
\text { nitrato de amonio). }\end{array}$ \\
\hline $\begin{array}{l}\text { Resolución Ministerial } \\
\text { que la puso en vigencia }\end{array}$ & Res. 277, D.O. 240, 23/dic/98. \\
\hline $\begin{array}{l}\text { Arancel aplicado por } \\
\text { salvaguardia }\end{array}$ & $0 \%$ \\
\hline $\begin{array}{l}\text { Arancel que } \\
\text { correspondería sin } \\
\text { salvaguardia }\end{array}$ & $15 \%$ \\
\hline $\begin{array}{l}\text { Empresas importadoras } \\
\text { según datos de } \\
\text { directorio de importadores } \\
\text { del BCR }\end{array}$ & Cemento de El Salvador \\
\hline $\begin{array}{l}\text { Importaciones de } \\
\text { fuera de C.A. }\end{array}$ & US\$ 275,553 \\
\hline $\begin{array}{l}\text { Pérdidas fiscales } \\
\text { totales } 1999-2000\end{array}$ & US\$ $\$ 1,332$ \\
\hline
\end{tabular}

El monto de las pérdidas fiscales asciende a 41,332 dólares, pudiéndose constatar que la única empresa importadora es el monopolio Cementos de El Salvador. Lá medida expiró el 31 de marzo del 2001, ya que no fue prorrogada por la resolución 73-2001, y por tanto, su arancel regresó al $15 \%$.

\section{iv. Sal yodada}

El 27 de mayo de 1997 se emitió la resolución 158 (D.O. 96, Tomo 335, 28/may/97) por los Ministros Hinds y Zablah Touché, en donde entre otras modificaciones arancelarias se le dio $0 \%$ de arancel a la subpartida 2501.00.91 que contempla el Cloruro sódico superior o igual al $97 \%$, pero inferior al $99.9 \%$ de pureza. 
Esta subpartida estaba anteriormente clasificada en la subpartida 25010090 , que tenía un arancel del $20 \%$, pero con la salvaguardia se aperturó una subpartida con el $0 \%$ (25010091), y se dejó en la otra (25010099) el arancel que le correspondía originalmente (20\%); por el programa de desgravación ese arancel del $20 \%$ se redujo hasta el $15 \%$.

\section{Cuadro No. 4 \\ Salvaguardia de sal yodada}

\begin{tabular}{|c|c|}
\hline Descripción & $\begin{array}{l}\text { Exención de aranceles para la } \\
\text { particla } 250100911 \text { (sal yodada). }\end{array}$ \\
\hline $\begin{array}{l}\text { Resolución Ministerial } \\
\text { (que la puso en vigencia) }\end{array}$ & $\begin{array}{l}\text { Res. } 158, \text { D.O. } 96, \text { Tomo } 335 \text {, } \\
28 / \text { may/97. }\end{array}$ \\
\hline $\begin{array}{l}\text { Arancel aplicado por } \\
\text { salvaguardia }\end{array}$ & $0 \%$ \\
\hline $\begin{array}{l}\text { Arancel que conresponderia } \\
\text { sin salvaguardia }\end{array}$ & $15 \%$ \\
\hline Empresas importacloras & $\begin{array}{l}\text { Según el Ministro de Economía, Miguel } \\
\text { Lacayo, en declaraciones a Diario El } \\
\text { Mundo ( } 21 / \text { dic/00) este producto sólo } \\
\text { lo utilizan dos empresas: Diana y } \\
\text { Bocadelli }\end{array}$ \\
\hline $\begin{array}{l}\text { Importaciones de fuera } \\
\text { de C.A. }\end{array}$ & US\$ $1,092,416$ \\
\hline $\begin{array}{l}\text { Pércliclass fiscales totaless } \\
1998-30 \text { de octubre } 2000\end{array}$ & US\$2 218,483 \\
\hline
\end{tabular}

Esta salvaguardia fue prorrogada por última vez por la resolución COMIECO 53-2000 hasta el 30 cle Octubre del 2,000, fecha en que expiró y se eliminaron las dos subparticlas que se habian aperturado: regresando la particla 25010090 al arancel original del 15\%, lo cuál confirma que este es el que clebería estar vigente sin salvaguardia.

\section{v. Cacao en polvo}

En ésta resolución se aducen que por los problemas que el Mitch ha creado en el abastecimiento de cacao, el país se ve en la 
obligación de liberar de impuestos a éste tipo de productos, por lo que se deja libres de impuestos (0\%) al cacao en polvo sin adición de azúcar ni otro edulcolorante, comprendidos en la partida 18050000 . Antes y después de la medida, el arancel era del 10\%, el cual era la meta centroamericana.

La resolución 101 que la puso en vigencia, se publicó en el Diario Oficial el 25 de mayo de 1999, por resolución de los Ministros de Economía y Hacienda de ese entonces, y fue prorrogada hasta una fecha muy posterior por el COMIECO (en la 39-99 del 17 de septiembre de 1999).

\section{Cuadro No. 5 \\ Salvaguardia de cacao en polvo}

\begin{tabular}{|c|c|}
\hline Descripción & $\begin{array}{l}\text { Exención de aranceles para la partida } \\
18050000 \text { (cacao en polvo sin adición } \\
\text { de azúcar ni otro edulcolorante). }\end{array}$ \\
\hline $\begin{array}{l}\text { Resolución Ministerial } \\
\text { que la puso en vigencia }\end{array}$ & $\begin{array}{l}\text { Res. } 101, \text { D.0.93, Tomo } 343,25 / \\
\text { may/99. }\end{array}$ \\
\hline $\begin{array}{l}\text { Arancel Aplicado por } \\
\text { salvaguardia }\end{array}$ & $0 \%$ \\
\hline $\begin{array}{l}\text { Arancel que correspondería } \\
\text { sin salvaguardia }\end{array}$ & $10 \%$ \\
\hline $\begin{array}{l}\text { Empresas importadoras } \\
\text { seguin directorio de } \\
\text { importadores BCR }\end{array}$ & $\begin{array}{l}\text { Foremost, Distribuidora Granada, } \\
\text { Cigarrería Morazán, Sabores Cosco, } \\
\text { Melher, Savon, etc. El Ministro Laca- } \\
\text { yo declaró a Diario fl Mundo ( } 21 \text { / } \\
\text { dic/00) que esta partida sólo era uti- } \\
\text { lizada por tres empresas }\end{array}$ \\
\hline $\begin{array}{l}\text { Importaciones de fuera } \\
\text { de C.A. }\end{array}$ & US\$ 877,222 \\
\hline $\begin{array}{l}\text { Pérdidas fiscales totales } \\
1999-2000\end{array}$ & US\$ 87,722 \\
\hline
\end{tabular}

Nota: Como la medida expiró el 30 de noviembre del 2000, no fue posible deducir en el mes de diciembre las estimaciones de las pérdidas fiscales. 
Esta medida contrasta con los decretos legislativos (267 y 270) que fueron emitidos por la Asamblea Legislativa para conceclerle exenciones de aranceles a todas las donaciones procedentes de zonas francas y de cualquier otro origen, que se destinaran a los damnificados del terremoto del 13 de enero y 13 de febrero del 2001. Es decir, a pesar de que en ambos casos se aducen situaciones extraordinarias para modificar temporalmente los aranceles, en una situación es la Asamblea Legislativa y en otra, los Ministros de Economía y Hacienda.

Por otro lado sería importante verificar si efectivamente los motivos muy concretos y específicos que se aducen en la medida (estragos del Mitch) efectivamente se cumplieron al inicio y persistieron hasta la fecha de expiración, o si por el contrario, ese motivo sólo constituyó una excusa para mantener una medida de apoyo a ciertas empresals.

\section{vi. Maderas}

Otras medicla de salvaguardia relevante es la que ha afectado a productos derivados de las maderas, que están comprendidos en el capítulo 44. Con esa salvaguardia, un número pequeño de particlas arancelarias han visto reducir sus aranceles. La medida de salvaguardia que afectó las maderas fue tomada principalmente por la resolución 157, D.O. 96 (parte II), Tomo 335, 28/mayo/97, que fue puesta en vigencia por los Ministros Fduardo Zablah Touché y Enrique Hinds, y se mantuvo por un periodo relativamente extendido de tiempo.

\section{vii. Textiles}

La resolución COMIECO 11-97 (del 11 de diciembre de 1997) establece que los textiles para el caso de El Salvador llegarán a los tramos de desgravación $(0,5,10$ y $15 \%)$ hasta el 2005, siendo uno de los productos que se han logrado mantener fuera del proceso de desgravación precisamente.

Sin embargo hace unos años se emitió una medida de salvaguardia (Res. 157, D.O. 96 parte II, Tomo 335, 28/mayo/97) en El Salvador que afectó a algunos productos de los capítulos textiles.

\section{8}


principalmente reduciendo los aranceles para ciertos insumos que se usan en la industria de la confección.

La medida abarcó a varias partidas arancelarias comprendidas entre el capítulo 52 al 63, que son en donde se clasifican los textiles y sus manufacturas; número relativamente reducido si se considera la gran cantidad de subpartidas que comprenden esos capítulos precisamente.

Los impactos fiscales de estas medidas pueden verse en el cuadro consolidado de los impactos fiscales en los capítulos correspondientes a textiles y sus manufacturas, además que en los anexos del trabajo se pueden ver detalles de las distintas subpartidas modificadas.

Esta medicla contrasta con los decretos legislativos (267 y 270) que fueron emitidos por la Asamblea Legislativa para concederle exenciones de aranceles a todas las donaciones procedentes de zonas francas y de cualquier otro origen, que se destinaran a los damnificados del terremoto del 1.3 de enero y 1.3 de febrero del 2001. Es decir, a pesar de que en ambos casos se aducen situaciones extraordinarias para modificar temporalmente los aranceles, en una situación es la Asamblea Legislativa y en otra, los Ministros de Economia y Hacienda.

Esta salvaguardia es de las que más tiempo permanecieron vigentes, y la gran mayoría de aranceles que fueron puestos por dicha medicla fueron converticlos en cambios permanentes del Arancel con la resolución COMIECO 73-2001, del 1/abr/01).

Con esta medicla puede resultar relativamente fácil para varias empresals textileras (no maquilas), que no han sido beneficiadas con rebajas arancelarias, percibir como aquellos que usen los insumos beneficiados por las salvaguardias pueden adquirir ventajas considerables.

Impacto económico de la discrecionalidad de la politica orancelaria en El Salvador

Digitalizado por Biblioteca "P. Florentino Idoate, S.J." Universidad Centroamericana José Simeón Cañas 
Cuadro No. 6

Salvaguardia de productos de hierro y acero

\begin{tabular}{|c|c|c|c|c|}
\hline Subpartida & Descripción & $\begin{array}{l}\text { Pérdidas } \\
\text { Fiscales }\end{array}$ & Periodo & $\begin{array}{l}\text { Empresas Importadoras } \\
\text { (según Directorio de Importadores) }\end{array}$ \\
\hline 72106110 & $\begin{array}{l}\text { - . De espesor superior } \\
\text { ighal a } 0.16 \mathrm{~mm} \text { pero } \\
\text { inferior } 0 \text { igual a } 2 \mathrm{~mm}\end{array}$ & 263,967 & $190 \% 20(x)$ & $\begin{array}{l}\text { Galvanis, } \\
\text { Consirumarket }\end{array}$ \\
\hline $7210(x) 10$ & $\begin{array}{l}\text { - . De espesor superior o } \\
\text { ighal a } 0.16 \mathrm{~mm} \text { pero } \\
\text { interior o igual a } 2 \mathrm{~mm}\end{array}$ & 17.860 & $199 \times 20(x)$ & Construmarket \\
\hline 7216.3190 & - Otros. & 41,700 & $190 \times 20(x)$ & $\begin{array}{l}\text { Zuniga, Ierreteril Az, } \\
\text { Montijes Electromecinicos de } \\
\text { C.A. Talleres Ferbe . Princl. } \\
\text { Siprein. Siemens Sal }\end{array}$ \\
\hline 7216.3200 & - p'erliles en 1. & 111,783 & $199620(x)$ & 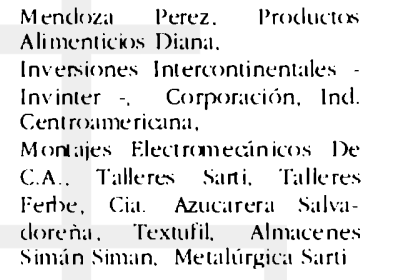 \\
\hline $7216.33(x)$ & - Perfiles en 11. & $148,7,3)$ & $100 \times 2000$ & $\begin{array}{l}\text { Ingenio El Car men, Montales } \\
\text { Electromecinicoss. Talleres Fer- } \\
\text { be. Cia. Azucarera Salvadorena, } \\
\text { Textufil }\end{array}$ \\
\hline $7216 \cdot 000$ & 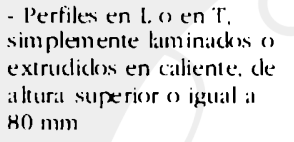 & 10.27 .3 & 19982000 & $\begin{array}{l}\text { Talleres Ferde, Corporacion } \\
\text { Ind.Centroamericana. Montiajes } \\
\text { Electromecanicos }\end{array}$ \\
\hline 72165000 & $\begin{array}{l}\text { - Los demais perfiles, } \\
\text { simplemente lam inackss o } \\
\text { extruclicks en caliente }\end{array}$ & 30.141 & $190 \times 2000$ & 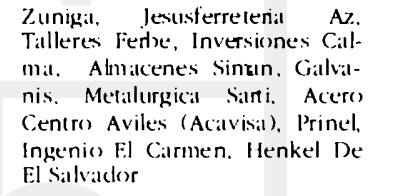 \\
\hline TOTAL. & & $62 \cdot 1.562$ & & \\
\hline
\end{tabular}

Nota: Todas las fracciones arancelarias han presentado reducciones arancelarias debido a medidas de salvaguardia.

\section{viii. Aceites}

El acuerdo biministerial 178, publicado el 31 de Marzo del 2000, por el Ministro de Economía, Miguel Lacayo, y el de Hacienda, José Luis Trigueros, puso en vigencia una reducción arancelaria para ciertos aceites. Sin embargo, esá salvaguardia fue adoptada por primera vez por el COMIECO hasta la resolución 53-2000, del 
31 de Julio del 2000. Este acuerdo 178 prorrogó el acuerdo biministerial anterior 634 del 16 de diciembre de 1999, aparecida en el Diario Oficial del 22 de diciembre de 1999, en dónde se tomaban medidas similares.

El acuerdo 178 "mantiene" la apertura y reducción arancelaria para los aceites refinados de soya (15079010) y girasol (15121910) importados granel, concediéndoles aranceles del 10\%, mientras que a otros $(15079090$ y 15121990$)$ que no fueran a granel se les dejó el $15 \%$. Anterior a la puesta en vigencia de la salvaguardia el Arancel Meta consolidado en Centroamérica era del 15\%, para las partidas 15079000 y 15121900 , en dónde se encontraban clasificadas todas las subpartidas anteriores.

Esta medicá expiró el 30 de noviembre del 2000, y por lo tanto fueron eliminadas las subpartidas que se habían abierto, regresando el arancel de las particlas originales al 15\%.

El impacto fiscal negativo para el Estado de la salvaguardia que redujo el arancel de estas dos subpartidas de aceites a granel, fue de aproximadamente US\$ 301,369 en el aceite de soya, y de US\$ 16,364 en el de girasol, en tan sólo un año de vigencia.

Hay que destacar que las modificaciones para aceites por medio de salvaguardias han sido constantes, clurante los últimos tres años; por ejemplo el acuerdo del COMIECO 13-97 de fecha 11 de diciembre de 1997 prorrogó por tres meses modificaciones parecidas en el rubro de aceites hechas por una salvaguardia anterior, puesta en vigencia por resoluciones ministeriales.

\section{ix. Productos de hierro}

Existen una gran cantidad de partidas arancelarias del capítulo 72, que corresponde a fundición de hierro y acero, que han sido beneficiadas con rebajas arancelarias por las salvaguardias.

La salvaguardia que redujo los aranceles para los productos de hierro y acero, fueron puestas en vigencia por las resoluciones ministeriales 157 y 158 , publicadas en el Diario Oficial del 28 de mayo de 1997; y se han mantenido desde entonces en su mayoría, convirtiéndose muchas de ellas en cambios permanentes del arancel, por resoluciones del COMIECO. 
Como puede ser visto, durante unos cuantos anos, las pérdiclas fiscales han sido relativamente importantes en este tipo de productos, y curiosamente se han mantenido las reducciones arancelarias derivadas de salvaguardias.

\section{x. Lácteos}

Los lácteos han sido de los productos que han visto alumentar los aranceles. como se verá en el apartado de los aumentos arancelarios. Sin embargo, para unas cuantas partidas arancelarias el sentido es inverso, pues se han reducido los aranceles, dejando pérdidas importantes para el Estado.

\section{Cuadro No. 7 \\ Salvaguardia de lácteos y derivados}

\begin{tabular}{|c|c|c|c|c|}
\hline Subpartida & Descripción & $\begin{array}{l}\text { Pérdidas } \\
\text { Fiscales }\end{array}$ & $\begin{array}{c}\text { Perio- } \\
\text { do }\end{array}$ & $\begin{array}{c}\text { Empresas Im portadoras } \\
\text { (Según Directorio de Importadores) }\end{array}$ \\
\hline 04022111 & $\begin{array}{l}\text { - - - En envase } \\
\text { de contenido } \\
\text { neto inferior a } 3 \\
\text { kg }\end{array}$ & 8,602 & $\begin{array}{l}1998 \\
2000\end{array}$ & No se detallal \\
\hline 04022121 & $\begin{array}{l}\text { - - - En envases } \\
\text { de contenido } \\
\text { neto inferior a } 5 \\
\text { kg }\end{array}$ & $2,027,560$ & $\begin{array}{l}1908 \\
2000\end{array}$ & $\begin{array}{l}\text { Summa Industrial. D'calsa, } \\
\text { Productos De Café-Nestlé, } \\
\text { New Zealand Milk Products Fil Salv. }\end{array}$ \\
\hline$(0+022122$ & $\begin{array}{l}\text { - - - En envalses } \\
\text { de contenido } \\
\text { neto superior o } \\
\text { igual a } 5 \mathrm{~kg}\end{array}$ & 1.218 .061 & $\begin{array}{l}1(x) 8 \\
2000\end{array}$ & $\begin{array}{l}\text { Summa Industrial, Productos Alimenticios } \\
\text { Diana, Productos De Cafe -Nestle El Sal- } \\
\text { vador. Industrias Quimicas, New } \\
\text { Zealand Milk Products, Empresas Lacteas } \\
\text { Foremost, Delicial }\end{array}$ \\
\hline 04022900 & - Las demás & 986,054 & $\begin{array}{l}1998- \\
2000\end{array}$ & $\begin{array}{l}\text { Sunma Industrial, Productos De Cafe } \\
\text {-Nestle, Arrocera San Francisco, Lacteos } \\
\text { Del Corral. Fmpresas Lacteas Foremost }\end{array}$ \\
\hline
\end{tabular}

En todos los casos las partidas han visto reducirse sus aranceles del 20\%, que tenian previamente, al 15\%, que fue establecido por la salvaguardia. Por lo tanto los montos de pérdidas son relativamente elevados, si consideramos que únicamente fue reducido un 5\% del arancel. Todas esas partidas corresponde a leches en polvo, granuladas o en estado sólido. 


\section{B. Segundo caso: Los incrementos arancelarios}

Para cuantificar el impacto de las mediclas que contemplaron incrementos arancelarios, parecería lógico estimar el saldo entre lo que las empresas hubieran tenido que pagar con los aranceles vigentes originales y lo que efectivamente han pagado con los mayores aranceles salidos de la salvaguardia. Las medidas de incrementos arancelarias tomadas por los Ministros habrían supuesto ingresos extraordinarios por parte del Estado, con la contrapartida de cobros y costos extraordinarios a las empresas importadoras de un determinado producto.

Sin embargo, en términos prácticos, existe la dificultad de que el aumento de los aranceles, en gran parte de los casos, ha pretendido impedir la importación de ciertos productos de fuera de la región centroamericaná y no necesariamente hacer que un agente efectivamente pague más. Las resultados de las estimaciones parecen confirmar eso, ya que los cobros extraordinarios totales son muy bajos, dado que en buen número de las partidas afectadas no se han registrado importaciones de fuera de la región centroamericana luego de la salvaguardia. Al aumentarse los aranceles a ciertos niveles, puede hacer que las importaciones se encarezcan a un punto que sean prohibitivas o poco competitivas con respecto a productos nacionales o aquellas importaciones de la región centroamericana que gocen de libre comercio, y en consecuencia los posibles importadores opten por hacer sus compras a nivel nacional. Debido a esa razones en varios casos resultó inútil querer estimar los ingresos fiscales "extraordinarios", pero se ha intentado hacer siempre que fue posible.

Los efectos negativos "fiscales" que han significado para algunas empresas el tener aranceles mayores debido a decisiones discrecionales podrían ser mejor estimados directamente por los afectados, al estimar los costos extraordinarios que les representaron sus compras nacionales, por sobre los costos en que habrían incurrido al importar con los aranceles inferiores - anteriores a la salvaguardia-. Las salvaguardias que aumentaron los aranceles obviamente tienen beneficiarios indirectos, y son aquellos sectores nacionales que producen bienes similares o competidores, y que podrían estar detrás de las medidas, los cuales no siempre son los sectores más 
sensibles de la economía, sino que, más bien, tienen capacidad de influencia en el Gobiernos.

Entre las mediclas de aumento de aranceles se encuentran embutidos (Ac. 1037, 1).O. 2, 4/ene/01), carnes (Ac. 51, D.0. 25, 4/ feb/00), azúcar (res. 346, D.O. 20, 30/ene/97), fertilizantes (res 165, D.O. 165, 13/jun/97), lácteos (Res. 7, D.O. 20, 30/ene/98), placals y láminas de plástico (res. 266, D.O. 96 parte II, 28/may/97) y arroz (Res. 318, D.O. 207, 8/nov/99).

\section{i. Caso del azúcar y otros endulzantes}

La última modificación del arancel al azúcar y otros productos endulzantes competitivos de ésta, fue al igual que los otros casos una resolución bi-ministerial, que aumentó al 40\% los derechos arancelarios para esos productos comprendiclos en el capítulo 17 del SAC. En concreto la medida fue puesta en vigencia por la res. 346 de 16 de diciembre del 1997, emiticla nuevamente por F. Hinds y Eduardo Zablah-Touché, que apareció en el Diario Oficial 20, tomo 338, del 30/ene/98.

En esta medida se aduce que es necesario salvaguardar los intereses de los diferentes sectores, que el azúcar es el segundo rubro de exportación, que se está sustituyendo a nivel mundial por otros productos, que existen clistorsiones a nivel mundial debido a subsidios, que los compromisos adquiridos ante la OMC permiten subir los aranceles hasta un máximo consoliclado, y finalmente se cita el artículo 26 del Convenio para justificar la posibilidad de emitir una salvaguardia para aumentar los aranceles.

Lo Ministros olvidaron en su supuesto "interés por proteger al azúcar nacional" mencionar que ni siquiera el acuerdo de la OMC les da la posibilidad de hacerlo por resoluciones, ya no se diga el artículo 26 del CRAAC. Si existiera algún tipo de competencia desleal o distorsiones por la invasión de productos, para emitir una salvaguardia o medida de protección hubieran tenido que aplicar mecanismos establecidos de mejor manera en el Reglamento Centroamericano sobre Medidas de Salvaguardia, o en el Reglamento Centroamericano sobre Prácticas de Comercio desleal. 
Cuadro No. 8

Salvaguardia de azúcar

\begin{tabular}{|c|c|c|c|c|}
\hline Subpartida & Descripción & $\begin{array}{c}\text { Arancel } \\
\text { aplicado por } \\
\text { Salvaguardia }\end{array}$ & $\begin{array}{l}\text { Arancel que } \\
\text { correspon- } \\
\text { deria sin } \\
\text { Salvaguardias }\end{array}$ & $\begin{array}{l}\text { Importaciones } \\
\text { fuera de C.A. } \\
\text { entre } \\
\text { 1998-2000 } \\
\text { (US\$) } \\
\end{array}$ \\
\hline 17011100 & - - De caña. & 40 & 20 & 67.211 \\
\hline 17011200 & - - De remolacha. & 40 & 20 & $\begin{array}{c}\text { No hay } \\
\text { importaciones }\end{array}$ \\
\hline 17019100 & $\begin{array}{l}- \text { - Con adición de } \\
\text { aromatizante o colorante. }\end{array}$ & 40 & 20 & 37,666 \\
\hline 17019900 & - - Los demás. & 40 & 20 & 178,448 \\
\hline 17022000 & $\begin{array}{l}\text { - Azuicar y jarabe de arce } \\
\text { ("maple"). }\end{array}$ & 40 & 10 & 135,147 \\
\hline 17023020 & $\begin{array}{l}\text { - Con un contenido de } \\
\text { fructosa, en estado seco, } \\
\text { inferior al } 20 \% \text { en peso. } \\
\text { - Glucosa y jarabe de } \\
\text { glucosa, con un contenido }\end{array}$ & 40 & 10 & 17,034 \\
\hline $\begin{array}{l}170240(0) \\
170250(0)\end{array}$ & $\begin{array}{l}\text { de fructosia, en estado } \\
\text { seco, superior o igtial al } \\
20 \% \text { pero inferior al } 50 \% \text {, } \\
\text { en peso } \\
\text { - Fructosa quimicamente } \\
\text { pura. }\end{array}$ & ' & 10 & 162 \\
\hline 17026000 & $\begin{array}{l}\text { - Las demás fructosas y } \\
\text { jarabe de fructosa, con un } \\
\text { contenido de fructosia. en } \\
\text { estado seco, superior al } \\
50 \% \text { en peso. }\end{array}$ & 40 & 10 & 973 \\
\hline 17029010 & $\begin{array}{l}\text { - - Maltosa químicamente } \\
\text { pura } \\
\text { - Otros azúcares y } \\
\text { jarabes, excepto los jarabes } \\
\text { de sacarosa y los } \\
\text { caramelizados. }\end{array}$ & 40 & 5 & $\begin{array}{c}\text { No hay } \\
\text { importaciones } \\
1.48,886\end{array}$ \\
\hline 17029090 & - - Otros. & 40 & 15 & 314,580 \\
\hline
\end{tabular}

Nota: Para considerar el arancel previo se tomaron los anteriores a cualquier salvaguardia, ya que algunas de esas partidas habían sido modificadas por previas medidas similares.

Según los datos encontrados, la medida fue prorrogada por el COMIECO por primera vez en la res. 24-98 que no tiene fecha, pero que debe haber sido en hecha entre el 31 de marzo de 1998 y el 29 de julio del 1998 según constan en el listado de resolucio- 
nes del COMIECO. La otra resolución importante del COMIECO al respecto es la 29-98, tomada el 18/dic/98, en dónde la totalidad de aranceles impuestos por la salvaguardia fueron convertidos en permanentes. Esa actuación es la que precisamente crea confusión para algunos importadores, ya que puede generar la impresión que la medida fue originada de una decisión del COMIECO, cuando en realidad entró en vigencia varios meses antes.

Las importaciones de fuera de la región centroamericana de los productos afectados por esta medida son relativamente pequeñas, pues, como se mencionó, en varios casos el aumento de aranceles pretendió. impedir la importación de los productos. En el caso del azúcar, es particularmente evidente que existen otras barreras para su importación, que han sido institucionalizados en otras legislaciones (vitamina A), la ley de comercialización del azúcar, el mantenimiento de barreras para su libre comercio en Centroamérica (Anexo A del Tratado General de Integración), su exclusión del calendario y la normativa del TLC con México. Las estimaciones de los "cobros fiscales extraordinarios" pueden ser vistos en el cuadro consolidado del impacto fiscal, en lo que corresponde al capítulo 17.

Ciertamente, el sector del azúcar es importante para la economía, y existen distorsiones muy grandes en los mercados mundiales en este tipo de productos, que pueden hacer necesario y váliclo el derecho de pedir protección para el sector; sin embargo eso no justifica que un funcionario tome esa medida por procedimientos indebidos, pues aquellos afectados bien pueden proceder legalmente contra sus decisiones, además que a los sectores que se pretende proteger se les deja con cierta inseguridad jurídica por los fundamentos legales de la medida.

En el azúcar existe relativamente una base más amplia de productores, que incluye cooperativas, pequenos, medianos y grandes productores, sin embargo en la agroindustria -ingenios- existe un oligopolio azucarero poderoso y organizado, con influencia en los círculos de gobierno, y que es quien maneja su procesamiento y su comercialización exterior e interior.

Fl tipo de estructuras oligopólicas, como las que existe en el sector azucarero, bien pueden hacer $-y$ de hecho lo hace- que el aumento de los aranceles no necesariamente deriven en benefi-

\section{6}


cio de los productores, consumidores y trabajaclores, o en mejoras de competitividad. El poder que les da su control del mercado les posibilita, que la simple protección arancelaria del sector sirva para consolidar su control oligopólico de los mercados, es decir mantener su dominio sobre sus proveedores (cooperativas, pequeños y medianos productores de cana), imponerse a los consumidores de azúcar y otros derivados (empresas y hogares), evitar la competencia entre los miembros (pacto de precios entre los ingenios), poder segmentar sus mercados internos y externos, e incluso desmejorar las condiciones laborales (flexibilizar condiciones laborales).

De ahí que resulta indispensable, en los mercados oligopólicos o monopólicos, como el azúcar, combinar las mediclas arancelarias con un marco juridico de libre competencia y de protección al consumidor que garanticen un manejo transparente de los aranceles, la protección de los intereses legítimos de los productores. agroindustrias, consumidores (hogares y empresas) y de la libre competencia en el sector.

El mareo jurídico de la libre competencial y de protección al consumidor son dos esferas que pueden contribuir mucho a una mayor transparencia en la conciliación de los diversos intereses que estarán en juego en una medicla arancelaria: $y$, por lo mismo. la carencia actual de esos marcos es un aspecto que contribuye a crear un ambiente poco transparente para las actuaciones de los funcionarios públicos.

Es importante mencionar que los motivos aducidos en los considerándos de la resolución del azúcar y de otros productos. sobre las distorsiones de los mercados mundiales, se restringen a un número muy limitado de productos, pues son pocals particlas las que tienen en la actualidad niveles arancelarios del $40 \%$ o o que ham experimentado incrementos. En la gran mayoria de particlas arancelarias, se aplicó un programa de desgravacion, que ni siquicra partió de un análisis sectorial pormenorizado de los mercado mundiales, de la estructura económica nacional, o de alguna planificatción estrátégică.

Por ejemplo, la gran mayoría de preductos del sector agropecuartios se encuentra por debajo del nivel arancelario del fo $10 \%$ a pesar de que existen productos como el mai blanco, que involucran a una

Impacto económico de la discrecionalidad de la politico arancelaria en El Salvodor 
gran cantidad de familias pobres y poseen una importancia cultural enorme; si el nivel arancelario es una muestra de la sensibilidad de un producto, podríamos afirmar que por la política arancelaria el azúcar es mucho más sensible que el maiz blanco. Otro buen ejemplo es que, mientras se dejan altos los aranceles para el azúcar y se les excluye de todos los Tratados de Libre Comercio, se pacta la apertura del mercado nacional de confites y clulces para México, lo que pone en desventaja a la industria nacional de esos productos, que tiene en el azúcar a un insumo fundamental.

Si bien no puede pedírsele al sector azucarero la defensa de los sectores relacionados, o la lucha contra la desgravación unilateral, es cierto que la falta de estudios de impacto y técnicos del proceso de desgravación y del mismo TLC con México, por parte de las autoridades económicas, impiden analizar la conveniencia de medidas de protección de un sector particular. Las medidas de protección que se han aplicado parecen responder más al poder de presión de grupos económicos que a la importancia de un producto concreto, y la aplicación aislada de estas en el contexto de la liberación del comercio exterior (desgravación y TLC) puede acalrrear grandes distorsiones en la economía nacional.

\section{ii. Lácteos}

Como fue mencionado, la gran mayoría de lácteos, sufrieron un aumento considerable de sus aranceles, siendo de los pocos productos que presentan aranceles del 40\%.

La salvaguardia fue puesta en vigencia por medio de la Res. 7 , D.O. 20, Tomo 338, 30/ene/98, la cual fue emitida por los Ministros Eduardo Zablah Touché y Enrique Hinds. Los motivos que se aducen para aplicar la salvaguardia son que este es un rubro importante, que se encuentra amenazado por el aumento de las importaciones, y por las distorsiones que existen a nivel internacional (subsidios) o en las condiciones para su importación. 
Cuadro No. 9

Salvaguardia de lácteos y sus derivados

\begin{tabular}{|c|c|c|c|}
\hline Partida & Descripción & \begin{tabular}{|c|} 
Arancel \\
aplicado \\
por \\
salvaguardia
\end{tabular} & $\begin{array}{c}\text { Arancel que } \\
\text { correspon- } \\
\text { deria sin } \\
\text { salvaguardia }\end{array}$ \\
\hline 04011000 & $\begin{array}{l}\text { - Con un contenido de materias } \\
\text { grasas inferior o igual al } 1 \% \text { en peso. }\end{array}$ & 40 & $15^{*}$ \\
\hline 04012000 & $\begin{array}{l}\text { - Con un contenido de materias grasas } \\
\text { superior al } 1 \% \text { pero inferior o igual al } 6 \% \text {, en } \\
\text { peso }\end{array}$ & 40 & $15^{*}$ \\
\hline 04013000 & $\begin{array}{l}\text { Con un contenido de materias } \\
\text { grasas superior al } 6 \% \text { en peso. }\end{array}$ & 40 & $15^{*}$ \\
\hline 04029110 & - - Leche evaporada. & 20 & 10 \\
\hline $\begin{array}{l}04029120 \\
04029190\end{array}$ & $\begin{array}{l}\text { - - Crema de leche. } \\
\text { - - Otras. }\end{array}$ & $\begin{array}{l}20 \\
20\end{array}$ & $\begin{array}{l}15^{*} \\
15^{*}\end{array}$ \\
\hline $\begin{array}{l}04029910 \\
04029990\end{array}$ & $\begin{array}{l}\text { - - Leche condensada. } \\
\text { - - Otras }\end{array}$ & $\begin{array}{l}20 \\
20\end{array}$ & $\begin{array}{c}10 \\
15^{*}\end{array}$ \\
\hline 04031000 & - Yogurt & 40 & 20 \\
\hline 04039010 & - - Suero de mantequilla & 40 & $15^{*}$ \\
\hline 04039090 & - - Otros. & 40 & $15^{*}$ \\
\hline 04049000 & - Los demás. & 30 & 10 \\
\hline 04051000 & - Mantequilla & 30 & $77^{*}$ \\
\hline 04052000 & - Pastas lácteas para untar. & 30 & $17^{*}$ \\
\hline 04059090 & -- Otras. & 20 & $17^{*}$ \\
\hline 04061000 & $\begin{array}{l}\text { - Queso fresco (sin madurar). incluido el del } \\
\text { lactosuero, y requesón }\end{array}$ & 40 & 20 \\
\hline 04062090 & -- Otros. & 40 & 20 \\
\hline $\begin{array}{l}04063000 \\
04064000\end{array}$ & $\begin{array}{l}\text { - Queso fundido, excepto el rallado o en polvo. } \\
\text { - Queso de pasta azul. }\end{array}$ & $\begin{array}{l}40 \\
40\end{array}$ & $\begin{array}{l}20 \\
20\end{array}$ \\
\hline
\end{tabular}

Nota: * En estas subpartidas el "Arancel previo a Salvaguardia" es el que les hubiera correspondido a esas partidas en la fecha en que se aplicó la salvaguardia, según el programa de desgravación de El Salvador, ya que éstas estaban incluidas en dicho programa. O en algunas otras, ese arancel corresponde al arancel establecido por una salvaguardia previa.

Igual que el caso anterior, es muy posible que el sector nacional de lácteos necesite de mayor protección arancelaria, dadas las gran- 
des distorsiones que pueden halerer en estos productos; sin embargo), de ahí no se puecle deducir que se justifique la adopción de una salvaguardial por mecanismos inclebidos.

La decisión de subir aranceles en estas partidas, contrasta con las rebajas hechas en otras particlas lácteas, como ya fue detallado. iDe doncle proviene ese trato diferente? aacaso existe un estudio ré(nico que fundamente la diferenciación del trato dado a las diferentes particlas:.

\section{iii. Productos cárnicos}

Fn ésta resolución se le aumenta el arancel al 30\% a diferentes tipos de carnes de bovinos (frescas, refrigeradas y congeladas); aduciendo gue el sector ganadero del país necesita de medidas arancelarias que garanticen certiclumbre para su desarrollo y de mayor capacidad para lograr un adecuado abastecimiento interno, se les asignan "clerechos arancelarios a la importación aclecuados a la importación del país".

Esta resolución fue emiticla por los Ministros de Hacienda, Economía y Agricultura y Ganadería, por medio del acuerdo 51, publicado en el Diario Oficial del 4 de febrero del 2000, y la resolución fue posteriormente prorrogada por el COMIECO en su resolución 5.3-2000) que entró en vigencia el 31 de julio del 2000.

Fl arancel anterior a la salvaguardia era del 15\%, que al mismo tiempo era la meta centroamericana, por lo que, como puede deducirse. la medida de hecho rompió con la equiparación ya lograda en el rubro entre los países de Centroamérica.

La medida estuvo poco tiempo vigente, ya que esta expiro el 1 de aloril del 2001, pues no fue prorrogada por la resolución COMIECO 73-2001, regresando todos los aranceles a su nivel previc) (lel $15 \%$. 
Cuadro No. 10

Aranceles de productos cárnicos y salvaguardia de El Salvador

\begin{tabular}{|c|c|c|c|c|c|c|c|}
\hline Partida & Descripción & $\begin{array}{c}\text { Costa } \\
\text { Rica }\end{array}$ & $\begin{array}{c}\text { El Salva- } \\
\text { dor }\end{array}$ & $\begin{array}{c}\text { Guate- } \\
\text { mala }\end{array}$ & $\begin{array}{l}\text { Hon- } \\
\text { duras }\end{array}$ & $\begin{array}{l}\text { Nica- } \\
\text { ragua }\end{array}$ & $\begin{array}{l}\text { Meta } \\
\text { centroame- } \\
\text { ricana }\end{array}$ \\
\hline 02011000 & $\begin{array}{l}\text { - En canales o } \\
\text { medials calnales. }\end{array}$ & 15 & $30 \mathrm{cs}$ & 15 & 15 & 10 & 15 \\
\hline 02012000 & $\begin{array}{l}\text { - Los demis } \\
\text { cortes (trozos) sin } \\
\text { deshuesar. }\end{array}$ & 15 & $30 \mathrm{cs}$ & 15 & 15 & 10 & 15 \\
\hline 02013000 & - Deshuesada. & 15 & $30 \mathrm{cs}$ & 15 & 15 & 10 & 15 \\
\hline 02021000 & $\begin{array}{l}\text { - En canaleso } \\
\text { medias canales. }\end{array}$ & 15 & $30 \mathrm{cs}$ & 15 & 15 & 10 & 15 \\
\hline 02022000 & $\begin{array}{l}\text { - Los demás } \\
\text { cortes (trozos) sin } \\
\text { deshuesar. }\end{array}$ & 15 & $30 \mathrm{cs}$ & 15 & 15 & 10 & 15 \\
\hline 020$) 23000$ & - Deshuesacla. & 15 & $30 \mathrm{cs}$ & 15 & 15 & 10) & 15 \\
\hline
\end{tabular}

Nota: Cs significa medida de salvaguardia. En este caso el arancel ubicatdo en "Meta Centroamericana" corresponde al que existiría en calso de no haber salvaguardia, y al mismo tiempo es el arancel previo a la emisión de salvaguardia, y posterior a la expiración cle la medicla.

\section{Tercer caso: Apertura de contingentes de desabastecimiento}

Existen algunos casos recientes en que las medidas de salvaguardia contemplan una combinación de aumentos y reducciones arancelarias simultáneamente para una misma partida arancelaria, y esos son los contingentes arancelarios, particularmente los de desabastecimiento. Estos consisten en que para determinados productos se determinan aranceles preferenciales y menores para una cuota o contingente, mientras que para las canticlades fuera de esals cuotas se fijan otros mayores.

En El Salvador se han abierto cuatro contingentes arancelarios, de los cuáles tres son de desabastecimiento: maíz blanco (Ac. 139 , D.O. 67, del 4/abr/00), arroz. (Res. 318, D.O. 207, 8/Nov/99) e insumos para embutidos (Res. 1037, D.O. 2, 4/ene/01). En estas medidas los contingentes con aranceles preferenciales han sido) 
dados exclusivamente para ciertos agentes, a condición de cumplir ciertos requisitos o de estar en una actividad económica, discriminánclose por lo tanto a otros agentes por diferentes motivos. Si consideramos que el concepto de franquicia, según el Protocolo al CAUCA de 1993, es "Exención total o parcial de los derechos e impuestos de importación que se otorga a las mercancias cuando éstas se importan en determinadas condiciones, o por señaladas personas, opara un fin determinado", esto significa que los contingentes de desabastecimiento en la forma que se han dado discriminando agentes_ se convierten fácticamente en una especie de franquicia para determinadas empresas. Por lo tanto, en este tipo de medidas puede haber simultáneamente en una misma partida agentes que se vean beneficiados por la reducción arancelaria de la salvaguardia, por la vía de ver reducidas sus tributaciones, en caso de tener acceso a la cuota, y por el otro lado empresas que se vean afectadas, por tener que pagar los aranceles más altos cuando no puedan acceder a los contingentes.

Es por esta particularidad que para cuantificar el impacto fiscal de las medidas de este tipo se ha optado por determinar el monto que los importadores beneficiarios deberían pagar por la cuota si se le aplicaran los aranceles mayores que están fuera de contingente y contrastar con el monto que esos importadores efectivamente pagaron con los aranceles menores y preferenciales dentro de la cuota. El saldo entre esas dos cantidades constituye la exención o el valor de la franquicia por una determinada cuota de productos que se le otorga únicamente a ciertos agentes económicos, cantidad que obviamente resulta en una pérdida fiscal para el Estado, y en una ganancia extraordinaria para las empresas beneficiarias. En estos casos, que constituye una mínima fracción, pues sólo ha sido posible estimar los impactos de dos contingentes de desabaste(imiento' (que corresponden a 2 subpartidas) se ha procedido a imputar como pérdida fiscal el monto total de la exención de aranceles del contingente de desabastecimiento; otra particularidad es que por ser un volumen físico determinado el que goza de la franquicia, en esals dos subpartidas se ha procedido a estimar el valor de la exención para los contingentes aprobados para el 2001 e imputar ese resultado a la estimación total. 


\section{i. El arroz}

En 1999 y 2000 se cerraron unas negociaciones para firmar un convenio de comercialización del arroz y sorgo entre los productores y la agroindustria, al parecer con participación de una importante gremial del agro².

Simultáneamente a la firma de ese convenio de comercialización, los actuales Ministros de Economía. Hacienda y Agricultura y Ganadería, Miguel Lacayo, José luis Trigueros y Salvador Irrutia respectivamente, emitieron una resolución ministerial y pusieron en vigencia una salvaguardia que abria un contingente de desabastecimiento para una particla de arroz, y subiendo los aranceles para otros partidas de ese cereal. La salvaguardia que moclifico los aranceles del arroz es la Res. triministerial 318 (lel 29-Oct-99) D.O. 207, Tomo 345 de fecha 8/Nov/99. Calsualmente el 3/nov/9) el COMIECO reunido en Toronto Canadá, emitió una resolución (COMIECO 47-99 Fx) sólo para Fl Salvador, en dónde hacía permanentes los incrementos arancelarios del arroz emitidos por las resolución tri-ministerial, medicla que fue publicada apresuradamente pues apareció el mismo día que la salvaguardia original $(8 / \mathrm{nov} / 99)$ ).

Con la medida se concedió la exención total de aranceles para la importación de un contingente de desabastecimiento de 550,000 quintales de arroz anuales de la particla 10061090, aduciendo que ese es el déficit nacional del productos. Este punto es particularmente ejemplificante de que la carencia de un reglamento que tipifique el desabastecimiento se presta para que pueda aducirse, como en este caso, un déficit nacional normal en un producto para invocar una salvaguardia por desabastecimiento, y que en otros ya vistos se aduzca déficit regional, o simplemente lineamientos para la política arancelaria.

Fl acceso al contingente es discriminatorio, pues tal como se desprende de las resoluciones, solo tienen derecho los beneficiadores de arroz a condición de cumplir ciertos requisitos - convenio de comercialización- mientras tanto el resto de importadores (que no) sean beneficiadores de arroz) o las importaciones por arriba de esa cuota deben pagar el $40 \%$ por sus importaciones de arroz de fuera de Centroamérica clasificadas en esa partida.

El contingente inicialmente establecido fue posteriormente aumen- 
tado a 717,000 quintales por el acuerdo tri-ministerial 884, DO 216, del 17/nov/00. El Acuerdo No. 61. D.O. 25, del 2/febrero/2001 estableció el contingente de desabastecimiento para el 2001 en 1,062,528 quintales, y mantuvo los términos generales de la medida.

\section{Cuadro No. 11 Salvaguardia del arroz}

\begin{tabular}{|c|c|c|}
\hline Contingente de arroz de la partida $1006 \mathrm{l}(0) 0$ & $\begin{array}{c}\text { I Inictid cle } \\
\text { Mecliclal }\end{array}$ & Valores \\
\hline $\begin{array}{l}\text { Importaciones proxedentes de lisA en ed } 20(x) \\
(100(1)](x)(0)\end{array}$ & Quintales & $\begin{array}{c}1.057 .54 \\
1\end{array}$ \\
\hline Aranced palgade dentro de contingente & $\% / 11$ & 0 \\
\hline Arancel fueral cle contingente & $1 \%$ & 10 \\
\hline \multicolumn{3}{|c|}{ Contingente inicial establecido para el 2,000 ( 550,000 quintales $)$} \\
\hline Vallor esilimzaclo del Cont ingente de 550.000 & $\$$ & 1.243 .11 \\
\hline 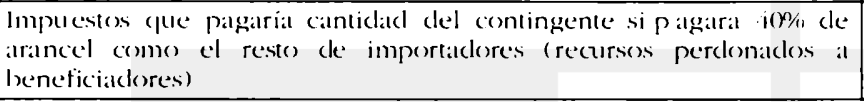 & $\$$ & $\begin{array}{l}1.697 .2 \cdot 1 \\
7\end{array}$ \\
\hline \multicolumn{3}{|c|}{ Contingente final distribuido en el 2,000 ( 717,000 quintales $)$} \\
\hline $\begin{array}{l}\text { Vialor estimades del contingente de } 717,000 \text { efectivamente } \\
\text { distribuido }\end{array}$ & $\$$ & $\begin{array}{c}5.5 .31,48 \\
2\end{array}$ \\
\hline 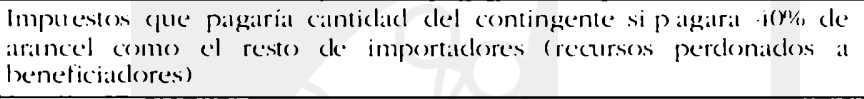 & $\$$ & $\begin{array}{c}2.212 .59 \\
3\end{array}$ \\
\hline \multicolumn{3}{|c|}{ Contingente de arroz establecido para el $2001(1,062,528$ quintales) } \\
\hline Valor estimaido del conlingente cke $1,(6,2,528$ aprobado paral el 2001 & $\$$ & $8.197,14$ \\
\hline $\begin{array}{l}\text { Impuestes que patgaria cantidad del contingente si palgara } 40 \% / 1 \text { de } \\
\text { arancel comos el resto de importadores (recursos perclonaclos a } \\
\text { beneficiadores) }\end{array}$ & $\$$ & $\begin{array}{c}3.278 .85 \\
8\end{array}$ \\
\hline Impacto fiscal total & & \\
\hline $\begin{array}{l}\text { Impacto fiscal total del Valor de impuestos } \\
\text { que pagaria contingente del } 2000 \text { y } 2001\end{array}$ & $\$$ & $\begin{array}{c}5.491 .45 \\
1\end{array}$ \\
\hline \multicolumn{3}{|c|}{ Importadores de la partida según directorio de im portadores BCR } \\
\hline 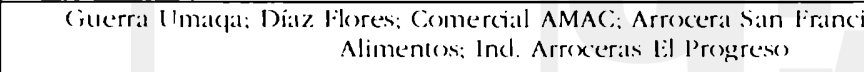 & $(0):($ & 1 \\
\hline
\end{tabular}

Fruente: Elaboración propia en base a datos del BCR.

Debido a que no se tiene información sobre cuáles son las empresas de ASALBAR, que agrupa a los beneficiadores de arroz signatarios del convenio de comercialización, no se puede saber a ciencia cierta cuáles de los importadores que aparecen el directorio del BCR son los importadores del contingente, y cuales son las empresas excluidas. 
El mencionado COMIECO 73-2001, fue el que hizo permanente a partir del $1^{\circ}$ de abril del 2001 el arancel del $0 \%$ para las cantidades dentro del contingente. "maquillando" el verdadero origen de la medida.

Como puede apreciarse, esta medida entra claramente dentro de la definición de franquicia que da el CAUCA, pues se da únicamente a ciertos agentes económicos, y, por tanto, es aún más obvio que no es atribución del Poder Ejecutivo darle vigencia, e incluso va en contra del artículo 21 del CRAAC, que prohibe las franquicias.

El monto de la franquicia concedida por los Ministros a los beneficiadores en el 2000 y 2001. no es nada despreciable, como puede verse en el cuadro, y representa una considerable cantidad de recursos que el Estado deja de percihir, en tan sólo dos años.

NOtAS

1. No se ha podido estimar los impactos de un tercero, que es el de insumos de embutidos, pues ha sido emitido para el 2001, y no se tienen datos suficientes para estimarlo.

2. En El Diario de Hoy del martes 27 de marzo del 2001, Pág. 59, "Experiencias exitosas en el sector agropecuario" por Ricardo Esmahan. Director Ejecutivo de CAMAGRO, se menciona que la gremial cuenta con un acuerdo de comercialización en el arrıo y otro del sorgo.

Impacto económico de la discrecionalidad de la politica arancelario en El Salvador

Digitalizado por Biblioteca "P. Florentino Idoate, S.J."

Universidad Centroamericana José Simeón Cañas 